\title{
Edaglitazone Sodium
}

National Cancer Institute

\section{Source}

National Cancer Institute. Edaglitazone Sodium. NCI Thesaurus. Code C72747.

The sodium salt form of edaglitazone, an agent belonging to the glitazone class of antidiabetic agents with antihyperglycemic activity. Edag litazone also appears to lower triglyceride and free fatty acid levels. 